\title{
Obstetric complications and risk of schizophrenia
}

\author{
Effect of gender, age at diagnosis and maternal history \\ of psychosis
}

\author{
HOLLIE V. THOMAS, CHRISTINA DALMAN, ANTHONY S. DAVID, \\ JOHAN GENTZ, GLYN LEWIS and PETER ALLEBECK
}

\begin{abstract}
Background Obstetric complications have been studied frequently as possible risk factors for schizophrenia.
\end{abstract}

\begin{abstract}
Aims To test the hypotheses that individual obstetric complications are most strongly associated with an increased risk of schizophrenia in males, in patients with an early age at first diagnosis and in subjects with a maternal history of psychosis.
\end{abstract}

Method Cases of schizophrenia diagnosed between January 197I and June 1994 were identified in the Stockholm County In-Patient Register. Controls were matched on age, gender, hospital of birth and parish of birth. Obstetric data were recorded blind to case-control status for 524 cases and 1043 controls.

Results This study did not find any large or consistent effect of gender, age at diagnosis or maternal history of psychosis on the risk of schizophrenia associated with individual complications.

\section{Conclusions Future studies should} examine these effects using a much larger sample that includes patients with schizophrenia and control subjects whose genetic risk of schizophrenia has been assessed accurately.

Declaration of interest No conflict of interest. Support from the Swedish Medical Research Council, the Stanley Foundation, the Söderberg-Königska Foundation and the Torsten and Ragnar Söderberg Foundation.

†See invited commentaries, pp. 415-416, this issue. †See pp. 403-408, this issue
The neurodevelopmental model of schizophrenia suggests that the condition results from early abnormal brain development due to genetic risk and/or environmental insults (Weinberger, 1987, 1995). Obstetric complications have been the most frequently studied early environmental insults that might act as possible risk factors. However, most babies with obstetric complications do not develop schizophrenia (Buka et al, 1993) and most patients with schizophrenia do not have a history of such complications. Therefore, the risk associated with obstetric complications might apply only to a certain group of patients with schizophrenia. We have examined the associations between a range of individual obstetric complications and risk of schizophrenia (Dalman et al, 2001, this issue). In this paper we test the hypotheses that individual obstetric complications are most strongly associated with an increased risk of schizophrenia in males, in patients with an early age at first diagnosis and in subjects with a maternal history of psychosis.

\section{METHOD}

\section{Study subjects}

A total of 648 cases of schizophrenia born in Stockholm County since January 1960 were identified through the Stockholm County InPatient Register. All cases received a diagnosis of schizophrenia between January 1971 and June 1994. Age at diagnosis was defined as the age at first admission with a diagnosis of schizophrenia. The control subjects were selected as the next two births following the birth of the case subject that were documented in the same parish records. The controls were further matched on year of birth (within 2 years for children born in the 1960s, within 1 year for children born after the 1960s), gender and hospital of birth. All control subjects were still residents of Stockholm County at the time of diagnosis of their matched case.
Of the identified cases, 51 had died, 32 were no longer living in Stockholm County, obstetric notes could not be retrieved for 37 cases $(6.5 \%)$ and 4 were excluded that lacked controls owing to a low number of births in that parish. Obstetric notes could not be retrieved for $89(7.9 \%)$ of the eligible controls. The present analyses include 524 cases of schizophrenia and 1043 matched controls for whom obstetric records were retrieved from the archives.

\section{Data collection}

The birth records were copied in the archives and given code numbers to conceal case/ control status, randomly assembled and given in batches to a midwife who extracted obstetric data according to a protocol devised by the research group. Signs of asphyxia at birth were defined as Apgar score $<7$ at 1, 5 or 10 min (Sykes et al, 1982; Silverman et al, 1985). For full information on definition of obstetric complications, see previous paper (Dalman et al, 2001, this issue).

The National In-Patient Register provided information on mothers who were admitted with a psychotic illness during 1971-1996 (coded 295-299 ICD-8 or 295-298 ICD-9, i.e. all non-organic psychoses; World Health Organization, 1967, 1978).

\section{Statistical analyses}

The frequency distribution of age at diagnosis was split approximately into thirds $(<23,23-27$ and $27+$ years). Odds ratios for schizophrenia in relation to individual obstetric complications were calculated for matched case-control sets using conditional logistic regression stratified by gender and stratified separately by the three categories of age at diagnosis. It was impossible to calculate odds ratios stratified by maternal history of psychosis while maintaining the matching, because maternal history was not a matching criterion. Instead, indicator variables that combined presence/absence of maternal history and presence/absence of each obstetric complication were created, with subjects with no maternal history and no record of each complication acting as the baseline in the odds ratio analyses. Tests for interaction between two variables were based on the likelihood ratio statistic. Exact $P$ values for tests of interaction are quoted in the text for signs of asphyxia at birth because this variable was demonstrated to be the only independent risk factor for 
schizophrenia in this data-set (Dalman et $a l, 2001$, this issue).

Ninety-five per cent confidence intervals (95\% CI) and two-sided $P$ values are quoted. Statistical tests were considered significant at $P<0.05$. All analyses were performed using Stata Version 5 (Stata Corporation, College Station, TX, USA).

\section{RESULTS}

\section{Characteristics of schizophrenia cases and control subjects}

Sixty-seven per cent of cases were male. The mean age at onset among the schizophrenia cases was 24.7 years (range 9-34 years). There were 173 cases with early age of onset of schizophrenia ( $<23$ years), 160 cases with an onset during 23-27 years of age and 191 with an onset later than 27 but before 35 years of age (the upper limit determined by the end of the follow-up period). The mean age of both the cases and controls was 29 years at the time of the study. A higher proportion of the mothers of cases than of controls had a history of psychotic illness $(9.2 \%$ v. $1.7 \% ; \chi^{2}=47.8$, d.f. $=1, P<0.001$ ).

\section{Odds ratios for schizophrenia stratified by gender}

The increase in risk of schizophrenia associated with asphyxia at birth, pre-eclampsia, head circumference less than $32 \mathrm{~cm}$ and being small for gestational age was greater in males than in females (Table 1). However, the $95 \% \mathrm{CI}$ around each odds ratio was wide and did not support any statistically significant difference in risk. None of the tests for interaction between gender and individual obstetric complications was statistically significant (test for interaction between gender and signs of asphyxia at birth, $P=0.84$ ).

\section{Odds ratio for schizophrenia stratified by age at diagnosis}

The estimate of schizophrenia risk associated with an instrumental delivery, an abnormal foetal heart rate and a gestation of less than 37 weeks was increased in those subjects diagnosed before 23 years of age (Table 2). However, the $95 \% \mathrm{CI}$ around each odds ratio was wide and did not support any statistically significant difference in risk. The only significant interaction was that between age at onset and a labour lasting more than $12 \mathrm{~h}\left(\chi^{2}=7.2\right.$, d.f. $=2$,
$P=0.03$; test for interaction between age at onset and signs of asphyxia at birth, $P=0.57$ ).

\section{Odds ratios for schizophrenia stratified by maternal history of psychotic illness}

Maternal history of psychotic illness was strongly associated with risk of schizophrenia (odds ratio $=5.9,95 \% \mathrm{CI}=3.3-$ 10.3). The increase in schizophrenia risk associated with an instrumental delivery was greater among those subjects with a maternal history of psychosis (Table 3). However, the $95 \%$ CIs did not support any statistically significant difference in risk. None of the tests for interaction between maternal psychotic history and individual complications was statistically significant (test for interaction between maternal history and signs of asphyxia at birth, $P=0.42$ ).

\section{DISCUSSION}

\section{Main findings}

This study tested the hypothesis that the risk of schizophrenia associated with individual obstetric complications would be increased in males and in patients with early onset, because these subgroups of patients are more likely to have a history of neurodevelopmental problems (Castle et al, 1993). Neither gender nor age at diagnosis had any large or consistent differential effect on the risk of schizophrenia associated with these factors. Therefore, the results provide little evidence to support the idea that males and patients with an early onset of schizophrenia are particularly susceptible to any single obstetric complication as infants that then increases their risk of neurodevelopmental problems, culminating in a diagnosis of schizophrenia.

Several studies previously have compared the proportion of male and female patients with schizophrenia who have a history of obstetric complications, or the proportion of patients with early and late disease onset who have a history of complications (Kirov et al, 1996; Verdoux et al, 1997; Smith et al, 1998). However, by simply comparing frequencies of complications between subgroups of patients with schizophrenia, these studies could not examine whether gender or age at onset actually modified the effect of any individual complication on schizophrenia risk.

Using a more appropriate analysis, three studies have reported the risk of early-onset schizophrenia associated with individual obstetric complications stratified by gender. Hultman et al (1999) reported that the risk associated with being small for gestational age was increased in males compared with females; the test for interaction between this variable and gender was statistically significant $(P<0.05)$. Dalman et al (1999) demonstrated that the risk of schizophrenia associated with pre-eclampsia, bleeding during pregnancy, a prolonged labour, uterine inertia, vacuum extraction, being small for gestational age and head circumference less than $32 \mathrm{~cm}$ was greater in males than in females. However, the $95 \%$ CIs did not support any statistically significant difference in risk and no statistical tests for interaction were carried out. Finally, Byrne et al (2000) reported a significant association between a history of a definite complication and an increased risk of schizophrenia among males presenting before the age of 30 years, whereas a history of definite complication was not associated significantly with schizophrenia in females at any age of presentation. In conclusion, no individual complication has been shown to be associated significantly with an increase in schizophrenia risk in both males and females, with the increase in risk among males being significantly greater than that among females.

Our study also aimed to examine the relative aetiological importance of genetic and early environmental risk factors within the neurodevelopmental model of schizophrenia. The results did not demonstrate any evidence to support a modification of the schizophrenia risk associated with obstetric complications by maternal history of psychotic illness.

The manner in which genetic factors and obstetric complications are associated with risk of schizophrenia could be explained by three possible mechanisms. First, obstetric complications might be aetiologically important only in those individuals who already carry some genetic predisposition (Mednick et al, 1987). Alternatively, obstetric complications alone might be sufficient to increase schizophrenia risk in at least some individuals (Murray et $a l, 1985)$. It has been suggested also that environmental and genetic risk factors are not completely independent of each other; instead, the obstetric complications might actually be the consequence of some genetic predisposition (Owen et al, 1988).

Marcelis et al (1998) used familial morbid risk of schizophrenia as an indicator of genetic liability to examine whether obstetric 
Table I Odds ratios (ORs)' for schizophrenia in relation to delivery complications, foetal growth and gestational age stratified by gender

\begin{tabular}{|c|c|c|c|c|c|c|c|c|}
\hline \multirow[t]{2}{*}{ Variable } & \multicolumn{4}{|c|}{ Males } & \multicolumn{4}{|c|}{ Females } \\
\hline & Cases & Controls & OR & $(95 \% \mathrm{Cl})$ & Cases & Controls & & $\mathrm{R}(95 \% \mathrm{Cl})$ \\
\hline \multicolumn{9}{|l|}{ Delivery complications } \\
\hline \multicolumn{9}{|l|}{ Labour (hours) } \\
\hline $0-12$ & 324 & 632 & 1.00 & & 159 & 319 & 1.00 & \\
\hline$>12$ & 25 & 65 & 0.75 & $(0.47-1.2 \mathrm{I})$ & 15 & 26 & 1.23 & $(0.62-2.4 I)$ \\
\hline \multicolumn{9}{|l|}{ Presentation $^{2}$} \\
\hline Normal & 323 & 647 & 1.00 & & 153 & 310 & 1.00 & \\
\hline Abnormal & 9 & 19 & 1.00 & $(0.44-2.29)$ & 7 & 12 & 1.20 & $(0.44-3.30)$ \\
\hline \multicolumn{9}{|l|}{ Instrumental delivery ${ }^{3}$} \\
\hline No & 326 & 644 & 1.00 & & 163 & 328 & 1.00 & \\
\hline Yes & 23 & 50 & 0.90 & $(0.53-1.53)$ & 10 & 15 & 1.43 & $(0.63-3.22)$ \\
\hline \multicolumn{9}{|l|}{ Cord around neck } \\
\hline No & 192 & 395 & 1.00 & & 101 & 190 & 1.00 & \\
\hline Yes & 116 & 228 & 1.08 & $(0.81-1.46)$ & 54 & 103 & 0.95 & $(0.61-1.47)$ \\
\hline \multicolumn{9}{|l|}{ Foetal heart rate } \\
\hline Normal & 327 & 656 & 1.00 & & 163 & 331 & 1.00 & \\
\hline$<100$ or $>160$ b.p.m. & 15 & 33 & 0.92 & $(0.49-1.73)$ & 3 & 6 & 1.50 & $(0.34-6.70)$ \\
\hline \multicolumn{9}{|l|}{ Asphyxia at birth ${ }^{4}$} \\
\hline No signs of asphyxia & 326 & 677 & 1.00 & & 168 & 338 & 1.00 & \\
\hline Signs of asphyxia & 22 & 17 & 2.76 & $(1.43-5.35)$ & 6 & 5 & 2.40 & $(0.73-7.86)$ \\
\hline \multicolumn{9}{|c|}{ Foetal growth and gestational age } \\
\hline \multicolumn{9}{|l|}{ Pre-eclampsia } \\
\hline No & 342 & 688 & 1.00 & & I7I & 341 & 1.00 & \\
\hline Yes & 8 & 10 & 1.60 & $(0.63-4.05)$ & 3 & 4 & 1.00 & $(0.18-5.46)$ \\
\hline \multicolumn{9}{|l|}{ Birth weight (g) } \\
\hline $0-2499$ & 15 & 18 & 1.69 & $(0.83-3.45)$ & 10 & II & 1.88 & $(0.78-4.56)$ \\
\hline $2500-4499$ & 328 & 654 & 1.00 & & 163 & 329 & 1.00 & \\
\hline \multicolumn{9}{|l|}{ Ponderal index $\left(\mathrm{g} / \mathrm{mm}^{3}\right)$} \\
\hline$<0.25$ & 74 & 158 & 0.91 & $(0.66-1.24)$ & 34 & 55 & 1.17 & $(0.73-1.90)$ \\
\hline $0.25+$ & 275 & 539 & 1.00 & & 140 & 290 & 1.00 & \\
\hline \multicolumn{9}{|l|}{ Head circumference $(\mathrm{cm})$} \\
\hline$<32$ & 18 & 28 & 1.39 & $(0.75-2.58)$ & 24 & 39 & 1.33 & $(0.76-2.3 I)$ \\
\hline $32-37$ & 309 & 631 & 1.00 & & 140 & 286 & 1.00 & \\
\hline \multicolumn{9}{|l|}{ Gestation (weeks) } \\
\hline$<33$ & 4 & 4 & 2.26 & $(0.49-10.42)$ & 2 & 1 & 4.00 & $(0.36-44.11)$ \\
\hline $33-36$ & 22 & 37 & 1.22 & $(0.70-2.14)$ & 8 & 18 & 0.83 & $(0.34-2.05)$ \\
\hline $37-42$ & 304 & 631 & 1.00 & & 157 & 309 & 1.00 & \\
\hline \multicolumn{9}{|l|}{ Small for gestational age } \\
\hline No & 317 & 652 & 1.00 & & 157 & 315 & 1.00 & \\
\hline Yes & 22 & 24 & 1.67 & $(0.93-3.01)$ & 10 & 16 & 1.22 & $(0.55-2.74)$ \\
\hline
\end{tabular}

I. Odds ratios estimated by conditional logistic regression for matched case-control sets.

2. Abnormal presentation includes breech presentation but not abnormal head presentation.

3. Instrumental delivery includes use of forceps, vacuum extraction and Caesarean section.

4. Signs of asphyxia based on complications expected to yield an Apgar score of $<7$ at I, 5 or $10 \mathrm{~min}$.

complications were associated positively with genetic predisposition in both psychosis and control probands. The authors found no significant associations between the complications and a family history of psychosis or schizophrenia, and concluded that it was unlikely that obstetric complications are purely the expression of genes predisposing to schizophrenia. This suggests that genetic risk and early environmental insults are more likely to be independent risk factors for schizophrenia. The results of our study did not provide any evidence to support an interaction between these two risk factors.

\section{Strengths and limitations of the study}

This study benefits from using obstetric data from birth records coded by a midwife blind to the case/control status of each subject, rather than relying on maternal recall. 
Table 2 Odds ratios (ORs)' for schizophrenia in relation to delivery complications, foetal growth and gestational age stratified by age at diagnosis

\begin{tabular}{|c|c|c|c|c|c|c|c|c|c|}
\hline \multirow[t]{2}{*}{ Variable } & \multicolumn{3}{|c|}{$<23$ Years } & \multicolumn{3}{|c|}{ 23-27 Years } & \multicolumn{3}{|c|}{$27+$ Years } \\
\hline & Cases & Controls & OR $(95 \% \mathrm{Cl})$ & Cases & Controls & OR $(95 \% \mathrm{Cl})$ & Cases & Controls & OR $(95 \% \mathrm{Cl})$ \\
\hline \multicolumn{10}{|l|}{ Delivery complications } \\
\hline \multicolumn{10}{|l|}{ Labour (hours) } \\
\hline $0-12$ & 165 & 308 & 1.00 & 144 & 302 & 1.00 & 174 & 341 & 1.00 \\
\hline$>12$ & 8 & 35 & $0.43(0.19-0.95)$ & 15 & 17 & $1.76(0.87-3.58)$ & 17 & 39 & $0.86(0.47-1.56)$ \\
\hline \multicolumn{10}{|l|}{ Presentation ${ }^{2}$} \\
\hline Normal & 156 & 316 & 1.00 & 145 & 294 & 1.00 & 175 & 347 & 1.00 \\
\hline Abnormal & 3 & 12 & $0.52(0.14-1.95)$ & 5 & 10 & I.II (0.37-3.32) & 8 & 9 & $1.70(0.63-4.60)$ \\
\hline \multicolumn{10}{|l|}{ Instrumental delivery ${ }^{3}$} \\
\hline No & 158 & 319 & 1.00 & 152 & 296 & 1.00 & 179 & 357 & 1.00 \\
\hline Yes & 15 & 23 & $1.34(0.68-2.64)$ & 7 & 22 & $0.58(0.24-1.40)$ & II & 20 & $1.09(0.49-2.39)$ \\
\hline \multicolumn{10}{|l|}{ Cord around neck } \\
\hline No & 92 & 205 & 1.00 & 90 & 174 & 1.00 & III & 206 & 1.00 \\
\hline Yes & 62 & 101 & $1.40(0.92-2.14)$ & 50 & 105 & $0.89(0.57-1.40)$ & 58 & 125 & $0.87(0.59-1.30)$ \\
\hline \multicolumn{10}{|l|}{ Foetal heart rate } \\
\hline Normal & 164 & 330 & 1.00 & 153 & 302 & 1.00 & 173 & 355 & 1.00 \\
\hline$<100$ or $>160$ b.p.m. & 6 & 9 & $1.50(0.52-4.32)$ & 3 & 14 & $0.39(0.11-1.40)$ & 9 & 16 & $1.22(0.5 \mathrm{I}-2.90)$ \\
\hline \multicolumn{10}{|l|}{ Asphyxia at birth ${ }^{4}$} \\
\hline No signs of asphyxia & 163 & 332 & 1.00 & 153 & 311 & 1.00 & 178 & 372 & 1.00 \\
\hline Signs of asphyxia & 9 & 9 & $2.00(0.79-5.04)$ & 7 & 7 & $2.31 \quad(0.71-7.47)$ & 12 & 6 & $4.00(1.50-10.66)$ \\
\hline \multicolumn{10}{|c|}{ Foetal growth and gestational age } \\
\hline \multicolumn{10}{|l|}{ Pre-eclampsia } \\
\hline No & 171 & 339 & 1.00 & 155 & 316 & 1.00 & 187 & 374 & 1.00 \\
\hline Yes & 2 & 5 & $0.80(0.16-4.12)$ & 5 & 3 & $3.33(0.80-13.95)$ & 4 & 6 & $1.33(0.38-4.72)$ \\
\hline \multicolumn{10}{|l|}{ Birth weight (g) } \\
\hline $0-2499$ & 6 & 12 & $0.98(0.35-2.78)$ & 9 & 8 & $2.30(0.84-6.24)$ & 10 & 9 & $2.22(0.90-5.47)$ \\
\hline $2500-4499$ & 164 & 321 & 1.00 & 149 & 301 & 1.00 & 178 & 361 & 1.00 \\
\hline \multicolumn{10}{|l|}{ Ponderal index $\left(\mathrm{g} / \mathrm{mm}^{3}\right)$} \\
\hline$<0.25$ & 29 & 75 & $0.74(0.46-1.18)$ & 41 & 68 & $1.27(0.81-1.99)$ & 38 & 70 & $1.09(0.71-1.68)$ \\
\hline $0.25+$ & 143 & 268 & 1.00 & 119 & 251 & 1.00 & 153 & 310 & 1.00 \\
\hline \multicolumn{10}{|l|}{ Head circumference $(\mathrm{cm})$} \\
\hline$<32$ & II & 23 & $1.05(0.49-2.27)$ & 14 & 22 & $1.33(0.65-2.68)$ & 17 & 22 & $1.65(0.83-3.30)$ \\
\hline $32-37$ & 157 & 314 & 1.00 & 137 & 282 & 1.00 & 155 & 321 & 1.00 \\
\hline \multicolumn{10}{|l|}{ Gestation (weeks) } \\
\hline$<33$ & 2 & 1 & $4.00(0.36-44.11)$ & 2 & 1 & - & 2 & 3 & $1.33(0.22-7.98)$ \\
\hline $33-36$ & 12 & 19 & $1.32(0.60-2.88)$ & 10 & 17 & $1.15(0.51-2.60)$ & 8 & 19 & $0.83(0.34-2.01)$ \\
\hline $37-42$ & 151 & 312 & 1.00 & 142 & 287 & 1.00 & 168 & $34 I$ & 1.00 \\
\hline \multicolumn{10}{|l|}{ Small for gestational age } \\
\hline No & 159 & 314 & 1.00 & 143 & 298 & 1.00 & 172 & 355 & 1.00 \\
\hline Yes & 7 & 17 & $0.80(0.33-1.93)$ & 12 & 14 & $1.75(0.80-3.84)$ & 13 & 9 & $2.43(1.02-5.80)$ \\
\hline
\end{tabular}

I. Odds ratios estimated by conditional logistic regression for matched case-control sets.

2. Abnormal presentation includes breech presentation but not abnormal head presentation.

3. Instrumental delivery includes use of forceps, vacuum extraction and Caesarean section.

4. Signs of asphyxia based on complications expected to yield an Apgar score of $<7$ at I, 5 or $10 \mathrm{~min}$.

The unique personal identification numbers allowed careful matching of cases and control subjects and verified that the control subjects were still residents of Stockholm County at the time of inclusion into the study, thus minimising selection bias.
Although our case-control study benefited from a large sample size, after stratifying by gender, age at diagnosis or maternal history of psychosis only very small numbers of subjects remained in each category who had also experienced any of the obstetric complications. Hence, we had little statistical power to examine the relationships very accurately. The tests for interaction were particularly prone to a lack of statistical power and their results should not be heavily relied upon. It is still 
Table 3 Odds ratios (ORs)' for schizophrenia in relation to delivery complications, foetal growth and gestational age stratified by maternal history of psychotic illness

\begin{tabular}{|c|c|c|c|c|c|c|c|c|}
\hline \multirow[t]{2}{*}{ Variable } & \multicolumn{4}{|c|}{ No maternal history } & \multicolumn{4}{|c|}{ Maternal history } \\
\hline & Cases & Controls & & $(95 \% \mathrm{Cl})$ & Cases & Controls & OR & $(95 \% \mathrm{Cl})$ \\
\hline \multicolumn{9}{|l|}{ Delivery complications } \\
\hline \multicolumn{9}{|l|}{ Labour (hours) } \\
\hline $0-12$ & 441 & 936 & 1.00 & & 42 & 15 & 5.93 & $(3.23-10.90)$ \\
\hline \multicolumn{9}{|l|}{ Presentation $^{2}$} \\
\hline Normal & 430 & 939 & 1.00 & & 46 & 18 & 5.11 & $(2.88-9.08)$ \\
\hline Abnormal & 16 & 31 & 1.22 & $(0.64-2.30)$ & 0 & 0 & - & \\
\hline \multicolumn{9}{|l|}{ Instrumental delivery ${ }^{3}$} \\
\hline No & 447 & 956 & 1.00 & & 42 & 16 & 5.41 & (2.99-9.78) \\
\hline Yes & 27 & 64 & 0.92 & $(0.57-1.48)$ & 6 & I & 12.09 & $(1.37-106.49)$ \\
\hline No & 265 & 572 & 1.00 & & 28 & 13 & 4.60 & $(2.24-9.45)$ \\
\hline Yes & 154 & 327 & 1.01 & $(0.78-1.30)$ & 16 & 4 & 10.42 & $(2.95-36.80)$ \\
\hline \multicolumn{9}{|l|}{ Foetal heart rate } \\
\hline Normal & 443 & 971 & 1.00 & & 47 & 16 & 6.83 & $(3.68-12.64)$ \\
\hline$<100$ or > 160 b.p.m. & 18 & 37 & 1.06 & (0.59-I.89) & 0 & 2 & - & \\
\hline \multicolumn{9}{|l|}{ Asphyxia at birth ${ }^{4}$} \\
\hline No signs of asphyxia & 450 & 998 & 1.00 & & 44 & 17 & 6.12 & $(3.38-11.08)$ \\
\hline Signs of asphyxia & 25 & 21 & 2.90 & $(1.58-5.35)$ & 3 & I & 2.07 & $(0.20-21.54)$ \\
\hline \multicolumn{9}{|c|}{ Foetal growth and gestational age } \\
\hline \multicolumn{9}{|l|}{ Pre-eclampsia } \\
\hline No & 468 & 1011 & 1.00 & & 45 & 18 & 5.47 & $(3.09-9.70)$ \\
\hline Yes & 8 & 14 & 1.25 & $(0.52-2.99)$ & 3 & 0 & - & \\
\hline $0-2499$ & 24 & 29 & 1.80 & $(1.02-3.17)$ & I & 0 & - & \\
\hline $2500-4499$ & 444 & 965 & 1.00 & & 47 & 18 & 5.72 & $(3.24-10.11)$ \\
\hline \multicolumn{9}{|l|}{ Ponderal index $\left(\mathrm{g} / \mathrm{mm}^{3}\right)$} \\
\hline$<0.25$ & 99 & 208 & 1.03 & $(0.79-1.35)$ & 9 & 5 & 3.52 & $(1.15-10.73)$ \\
\hline $0.25+$ & 376 & 816 & 1.00 & & 39 & 13 & 6.87 & $3.51-13.48)$ \\
\hline \multicolumn{9}{|l|}{ Head circumference $(\mathrm{cm})$} \\
\hline$<32$ & 39 & 66 & 1.35 & $(0.88-2.06)$ & 3 & I & 4.64 & $(0.47-45.97)$ \\
\hline $32-37$ & 410 & 901 & 1.00 & & 39 & 16 & 5.43 & $(2.94-10.03)$ \\
\hline \multicolumn{9}{|l|}{ Gestation (weeks) } \\
\hline$<33$ & 6 & 5 & 3.05 & $(0.83-I I .30)$ & 0 & 0 & - & \\
\hline $33-36$ & 28 & 54 & 1.10 & $(0.67-1.80)$ & 2 & I & 3.82 & $(0.33-44.34)$ \\
\hline $37-42$ & 417 & 923 & 1.00 & & 44 & 17 & 5.88 & $(3.26-10.61)$ \\
\hline \multicolumn{9}{|l|}{ Small for gestational age } \\
\hline No & 430 & 949 & 1.00 & & 44 & 18 & 5.06 & $(2.84-9.01)$ \\
\hline Yes & 31 & 40 & 1.51 & $(0.93-2.44)$ & I & 0 & - & \\
\hline
\end{tabular}

I. Odds ratios estimated by conditional logistic regression for matched case-control sets. Odds ratios use baseline state of no maternal history and no history of the individual complication.

2. Abnormal presentation includes breech presentation but not abnormal head presentation.

3. Instrumental delivery includes use of forceps, vacuum extraction and Caesarean section.

4. Signs of asphyxia based on complications expected to yield an Apgar score of $<7$ at I, 5 or $10 \mathrm{~min}$

possible that gender, age at diagnosis or genetic risk might alter the association between signs of asphyxia at birth and schizophrenia risk that we have reported (Dalman et al, 2001, this issue), but very large studies would be needed to detect this.

Unfortunately our only measurement of genetic risk of schizophrenia was a recorded maternal history of psychosis; data on paternal history would have improved the measurement. It is likely that the transmission of predisposing genes to schizophrenia does not necessarily result in the overt manifestation of the disorder 
(Gottesman \& Bertelsen, 1989; Cannon et al, 1994), so even having full knowledge of maternal and paternal history of overt psychosis would not be an ideal measurement of genetic risk. The ideal measurement would require the identification of the genetic factors necessary for schizophrenia development, or at least markers that are very closely linked to them.

In conclusion, this study did not find any large or consistent effect of gender, age at diagnosis or maternal history of psychotic illness on the risk of schizophrenia associated with individual obstetric complications and indicators of foetal growth. Future studies should aim to examine these effects using a much larger study sample that includes patients with schizophrenia and control subjects whose genetic risk of schizophrenia has been assessed accurately.

\section{ACKNOWLEDGEMENTS}

We thank Professor Johan Cullberg, MD, for valuable comments. We thank Birger Winblad, MD, for assessing records and Charlotta Grunewald, MD for obstetric advice. We also thank Dr Karin Nyberg for sharing her knowledge on obstetric case records and working routines. We are grateful to Aslög Malmberg, MRCPsych, for her help in designing the study and to the midwives Gunilla Lilja and Asa Weitzberg for assessing records.

\section{REFERENCES}

Buka, S. L., Tsuang, M. T. \& Lipsitt, L. P. (1993) Pregnancy/delivery complications and psychiatric diagnosis: a prospective study. Archives of General Psychiatry, 50, I5I-I56.

Byrne, M., Browne, R., Mulryan, N., et al (2000) Labour and delivery complications and schizophrenia. Case-control study using contemporaneous labour ward records. British Journal of Psychiatry, 176, 531-536.

Cannon, T. D., Zorrilla, L. E., Shtasel, D., et al (1994) Neuropsychological functioning in siblings discordant for schizophrenia and healthy volunteers. Archives of General Psychiatry, 5I, 65I-66I.

Castle, D. J., Wessely, S. \& Murray, R. M. (1993) Sex and schizophrenia: effects of diagnostic stringency, and associations with premorbid variables. British Journal of Psychiatry, 162, 658-664.

Dalman, C., Allebeck, P., Cullberg, J., et al (1999) Obstetric complications and the risk of schizophrenia. Archives of General Psychiatry, 56, 234-240.

_ , Thomas, H. V., David, A. S., et al (200I) Signs of asphyxia at birth and risk of schizophrenia. British journal of Psychiatry, 179, 403-408.

Gottesman, I. I. \& Bertelsen, A. (1989) Confirming unexpressed genotypes for schizophrenia. Risks in the offspring of Fischer's Danish identical and fraternal discordant twins. Archives of General Psychiatry, 46, 867-872.

\section{CLINICAL IMPLICATIONS}

- The increased risk of schizophrenia associated with asphyxia at birth was not modified significantly by gender, age at diagnosis or maternal history of psychosis.

- A more conclusive investigation of such interactions would require a much larger population-based sample.

A sufficiently sized sample for a stratified analysis might be generated only by a meta-analysis of individual patient data.

\section{LIMITATIONS}

Statistical power was limited after stratifying by gender, age at diagnosis or maternal history of psychosis.

- Our only indicator of genetic risk of schizophrenia was a recorded maternal history of psychosis.

- Age at diagnosis was defined as age at first in-patient admission with a diagnosis of schizophrenia.

HOLLIE V. THOMAS, DPhil, Department of Psychological Medicine, University of Wales College of Medicine, Cardiff; CHRISTINA DALMAN, MD, Community Medicine, Unit for Psychosis Research, Stockholm, Sweden; ANTHONY S. DAVID, FRCPsych, Institute of Psychiatry and GKT School of Medicine, London; JOHAN GENTZ, MD, Sachsska Children's Hospital, Stockholm, Sweden; GLYN LEWIS, FRCPsych, University of Wales College of Medicine, Cardiff; PETER ALLEBECK, MD, Department of Social Medicine, University of Göteborg, Sweden

Correspondence: Dr H.V.Thomas, Psychological Medicine Academic Unit, 2nd Floor Monmouth House, Heath Park, Cardiff CFI4 4XN, UK. Tel: 0292074 3229; fax: 0292074 6595;

e-mail: thomashv@cardiff.ac.uk

(First received 10 August 2000, accepted 21 August 2000)

Hultman, C. M., Sparén, P.,Takei, N., et al (1999) Prenatal and perinatal risk factors for schizophrenia, affective psychosis, and reactive psychosis of early onset: case-control study. British Medical Journal, 318,421-426.

Kirov, G., Jones, P. B., Harvey, l., et al (1996) Do obstetric complications cause the earlier age at onset in male than female schizophrenics? Schizophrenia Research, 20, $117-124$.

Marcelis, M., van Os, J., Sham, P., et al (1998) Obstetric complications and familial morbid risk of psychiatric disorders. American Journal of Medical Genetics (Neuropsychiatric Genetics), 8I, 29-36.

Mednick, S. A., Parnas, J. \& Schulsinger, F. (1987) The Copenhagen high-risk project. Schizophrenia Bulletin, I3, 485-495.

Murray, R. M., Lewis, S. W. \& Reveley, A. M. (1985) Towards an aetiological classification of schizophrenia. Lancet, 4I, 1023-1026.

\section{Owen, M. J., Lewis, S.W. \& Murray, R. M. (1988)}

Obstetric complications and schizophrenia: a computed tomographic study. Psychological Medicine, 18, 331-339.

Silverman, F., Suidan, J., Wasserman, J., et al (1985) The Apgar score: is it enough? American Journal of Obstetrics and Gynecology, 66, 331-336.
Smith, G. N., Kopala, L. C., Lapointe, J. S., et al (1998) Obstetric complications, treatment response and brain morphology in adult-onset and early-onset males with schizophrenia. Psychological Medicine, 28,645-653.

Sykes, G. S., Johnson, P., Ashworth, F., et al (1982) Do Apgar scores indicate asphyxia? Lancet, 27, 494-496.

Verdoux, H., Geddes, J. R., Takei, N., et al (1997) Obstetric complications and age at onset in schizophrenia: an international collaborative metaanalysis of individual patient data. American journal of Psychiatry, 154, 1220-1227.

Weinberger, D. R. (1987) Implications of normal brain development for the pathogenesis of schizophrenia. Archives of General Psychiatry, 44, 660-669.

- (1995) From neuropathology to neurodevelopment. Lancet, 346, 552-557.

World Health Organization (1967) Manual of the International Statistical Classification of Diseases, Injuries and Causes of Death (8th revision) (ICD-8). Geneva: WHO.

- (1978) Manual of the International Statistical Classification of Diseases, Injuries and Causes of Death (9th revision) (ICD-9). Geneva: WHO. 